
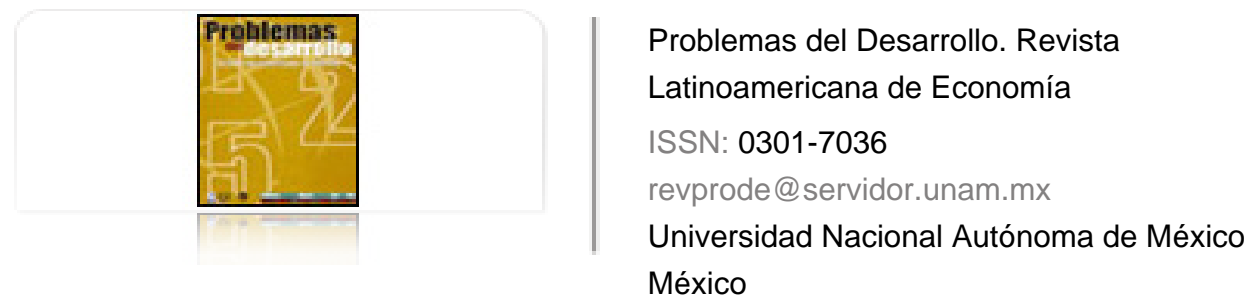

Horbath, Jorge Enrique

Balance de la competencia entre México y China en el mercado estadounidense Problemas del Desarrollo. Revista Latinoamericana de Economía, vol. 36, núm. 143, octubrediciembre, 2005, pp. 145-169

Universidad Nacional Autónoma de México

Distrito Federal, México

Disponible en: http://www.redalyc.org/articulo.oa?id=11820081007

Cómo citar el artículo

Número completo

- Más información del artículo

Página de la revista en redalyc.org

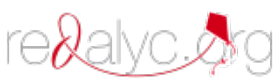

Sistema de Información Científica

Red de Revistas Científicas de América Latina, el Caribe, España y Portugal Proyecto académico sin fines de lucro, desarrollado bajo la iniciativa de acceso abierto 


\section{Balance de la competencia entre México y China en el MERCADO ESTADOUNIDENSE*}

\section{Jorge Enrique Horbath**}

Fecha de recepción: 6 de marzo de 2005. Fecha de aceptación: 28 de octubre de 2005.

\section{Resumen}

En los últimos años se reconoce la amenaza que representa China como claro competidor de México y de otros países por la captación de capital extranjero para financiar su proceso de integración a la economía occidental. Este documento pretende dar cuentas de este fenómeno e insistir en que, más allá del temor desatado por la atracción que puede hacer el país asiático a las empresas maquiladoras, la preocupación debe concentrarse en un plan de modernización, innovación tecnológica y reestructuración productiva para reindustrializar a México, a la par de un mejor aprovechamiento comercial que reduzca el nivel de dependencia con la economía estadounidense. Estas transformaciones deben basarse en estrategias de inclusión social, con capacidad para reducir la pobreza y generar mejores condiciones en la senda del desarrollo.

Palabras clave: macroeconomía, comercio internacional, competitividad, inversión extranjera, política económica.

* Este documento fue elaborado con recursos físicos y financieros de la Facultad Latinoamericana de Ciencias Sociales (FlACSO) México, dentro del marco del proyecto "Aprendizaje tecnológico y escalamiento industrial de la industria maquiladora de exportación”, financiado por CONACYT.

* Profesor investigador de la FLACSO México, forma parte de la red de investigadores de la Secretaría del Trabajo y Previsión Social. Correo electrónico: jhorbath@flacso.edu.mx. 


\begin{abstract}
In recent years, the threat represented by China has been recognized as a clear competitor to Mexico and other countries competing to attract foreign capital to finance its integration process into the economies of the west. This document attempts to account for the phenomenon of the trade threat posed by China. And besides the fears that have been unleashed by the attraction of the maquiladoras to that Asian country, concerns should be concentrated on a plan of modernization and technological innovation as well as productive restructuring to reindustrialize Mexico, parallel with better commercial application to reduce the level of dependence on the U.S. economy. However, at the same time, these transformations should be based on strategies of social inclusion, which could have the capacity to reduce poverty and generate better conditions for an improved development path.
\end{abstract}

Key words: competition; U.S. market; integration.

\title{
Résumé
}

On reconnaît ces dernières années la menace que représente la Chine comme un clair concurrent du Mexique et d'autres pays qui concurrencent pour la captation de capital étranger pour financer leur processus d'intégration à l'économie occidentale. Ce document prétend rendre compte du phénomène de menace commerciale représenté par la Chine et qui, bien plus loin de la crainte qui a surgit par l'attirance des entreprises de sous-traitance par ce pays asiatique, la préoccupation doit se concentrer sur un plan de modernisation et d'innovation technologique ainsi que dans la restructuration productive pour réindustrialiser le Mexique, parallèlement à une meilleure exploitation commerciale qui réduirait le niveau de dépendance vis à vis de l'économie des Etats Unis d'Amérique. Cependant, ces transformations devraient se baser sur des stratégies d'inclusion sociale capables de réduire la pauvreté et de générer de meilleures conditions pour un meilleur chemin de développement. Mots-cléfs: concurrence, marché des Etats Unis d'Amérique (marché américain), intégration.

\section{Resumo}

Nos últimos anos aceita-se a ameaça que a China representa, como um claro competidor do México e de outros países que compitem pela captação de capital estrangeiro para financiar seu processo de integração à economia ocidental. Este documento pretende apresentar contas do fenómeno de ameaça comercial da China e que além do temor que tem se criado pela atração das empresas maquiadoras que este país asiático pode fazer, a preocupação debe se concentrar num plano de modernização e inovação tecnológica e reestruturação produtiva para reindustrializar o México e ao mesmo tempo dum melhor proveito comercial que diminua o nivel de dependência com a economia dos Estados Unidos, mas que à sua vez ditas transformações estejam baseadas em estratégias de inclusão social, que possam ter a capacidade de reduzir a pobreza e gerar melhores condições para um melhor caminho de desenvolvimento.

Palavras chave: competência, mercado americano, integração.

\section{Desarrollo}




\section{Introducción}

$\mathrm{E}$

n los últimos años, se reconoce la amenaza que representa China como un claro

competidor de México y de otros países por la captación de capital extranjero

para financiar su proceso de integración a la economía occidental. Dicha amenaza es mayor cuando se piensa en su capacidad para desplazar rivales de sus productos dentro de mercados tan grandes y competitivos como el estadounidense. Este documento pretende mostrar el grado de antagonismo que hay entre México y China dentro de dicho mercado e identificar los componentes de su capacidad exportadora, los sectores productivos y los productos en los cuales cada uno tiene ventajas. Se efectuará una revisión de las principales características de los mercados mexicano y chino en las últimas décadas, resaltando su condición económica y social al final del siglo xx. Posteriormente, se realiza una evaluación de su desempeño comercial, presentando el perfil general de cada uno de ellos en el comercio mundial, la posición y los cambios dentro del comercio exterior de cada nación. Finalmente, se efectúa un diagnóstico de la forma en la cual ambos países lograron penetrar el mercado estadounidense, mostrando la trayectoria con que China logró desplazar a México como principal socio comercial de Estados Unidos. Se efectuará una comparación de las ventajas comerciales de México y China en cada mercado/producto, resaltando la manera en que los dos países compiten dentro del, hasta hace pocos años, régimen maquilador, correspondiente a la fracción arancelaria 9802 del sistema armonizado. Con esta revisión, se pretende dar cuenta de ese fenómeno e insistir en que, más allá del temor que se ha desatado por la atracción que puede hacer la nación asiática de las empresas maquiladoras, la preocupación de México debe concentrarse en un plan de modernización e innovación tecnológica y reestructuración productiva para reindustrializar al país, a la par de un mejor aprovechamiento comercial que reduzca el nivel de dependencia respecto de la economía estadounidense, pero basado en estrategias de inclusión social con capacidad para reducir la pobreza y generar mejores condiciones de desarrollo.

\section{Trayectorias económicas y sociales de los dos competidores}

La capacidad competitiva de los países es resultado tanto de su historia económica como de sus transformaciones, pero mucho más de aquellos cambios que, en su momento, sirvieron para forjar un camino que les permitiera acceder a un posicionamiento comercial en la esfera económica mundial. En las dos últimas décadas, México ha tratado de realizar reformas económicas que le garanticen menor exposición al persistente riesgo de crisis y 
aprovechar el potencial que tiene con la firma de un cúmulo de convenios comerciales, entre los que destaca el Tratado de Libre Comercio de América del Norte (TLCAN). Por su parte, China empezó sus reformas desde la década de los años setenta, con una visión de largo plazo, buscando transformaciones controladas y planificadas dentro de su sistema económico, sin que esto implicara riesgos a su estabilidad social. A continuación se exponen las principales transformaciones y reformas económicas de los dos países y se presenta una comparación de sus más destacados indicadores económicos y sociales.

\section{Reformas económicas de México y China}

Hace aproximadamente dos décadas se inició en México una serie de cambios y transformaciones dentro del ámbito económico y político, cuyo eje articulador ha sido la redefinición de la relación del Estado con la sociedad. En 1983 comenzó el proceso de reformas estructurales con el fin de sanear las finanzas públicas y estabilizar las variables macroeconómicas. Las principales medidas tomadas para alcanzar tales objetivos fueron: liberación del comercio exterior, desregulación económica (telecomunicaciones y petroquímica, entre las áreas más importantes) y desincorporación de las empresas del sector público. A partir de 1986 empezó la negociación y firma de convenios comerciales y tratados de libre comercio, a la fecha 32, con diversos países en tres continentes, siendo el más importante el firmado con Estados Unidos y Canadá en 1993. Entre 1989 y 1993 se profundizó el proceso de apertura comercial y disminuyeron aun más los aranceles promedio y los permisos de importación.

Otras reformas implantadas por el gobierno mexicano para estabilizar las variables macroeconómicas y redefinir el papel del Estado en la economía fueron la apertura a la inversión extranjera, la flexibilización del tipo de cambio y la autonomía del banco central. Tanto esas medidas, como la liberación del comercio exterior, la desregulación económica y la desincorporación de las empresas del sector público han tenido efectos desiguales y diferenciados en distintos periodos; sin embargo, a veinte años de iniciadas esas transformaciones, los resultados distan mucho de ser óptimos. Ciertamente, la economía mexicana ha alcanzado un alto nivel de estabilidad en sus variables macroeconómicas, reducido su déficit fiscal y la inflación, consolidado las reservas internacionales, lo cual se ha traducido en niveles de credibilidad más altos por parte de la comunidad internacional, a diferencia de lo ocurrido durante la década de los ochenta. La acelerada apertura comercial trajo beneficios principalmente a las grandes empresas en algunos sectores de la actividad económica. En 1999, de acuerdo con el Programa de Política Industrial y Comercio Exterior, $90 \%$ de las exportaciones directas lo realizaba $10 \%$ de las empresas, lo cual habla del alto grado de concentración de la actividad exportadora. Ello ha causado graves desequilibrios en la planta productiva nacional. Por otra parte, los incrementos en las exportaciones de México se basan no tanto en la productividad como en los bajos

\section{DeSarrollo}


salarios y el tipo de cambio, lo que disminuye las posibilidades de bienestar y desarrollo social. ${ }^{1}$

La transformación de China para incorporarse al mercado mundial es un proceso que lleva ya tres décadas y aún no termina. Su base fue una economía saneada, con inflación de $0.7 \%$, magnitud del déficit público de $1.1 \%$, superávit en balanza de pagos y crecimiento económico cercano a $8 \%$ en 1978. Ello no implicó efectuar ajustes macroeconómicos que incorporaran políticas de estabilización antes de dar paso a las propias reformas, lo cual hace de China una excepción histórica, un caso verdaderamente raro. Asimismo, el menor sesgo hacia una estructura industrializada y su marco demográfico le han dado la oportunidad para desplegar crecimientos notorios, en los cuales la estructura empresarial, predominantemente conformada por PYMES, con un sistema flexible de planificación central y baja vinculación comercial con el COMECON, debido a las diferencias ideológicas con la entonces URSS, lo cual provocaba que $86 \%$ de sus exportaciones se dirigiera a socios con economías de mercado, dejando solamente $14 \%$ de su comercio en esa región. Los inconvenientes de los modelos de planeación central, como el soviético, fueron menos pronunciados en China, de manera que el país disponía de mayores posibilidades de crecimiento en la agricultura y la industria ligera, de más opciones para modificar el comportamiento de las empresas y, de modo general, de un sistema más flexible (Shirk, 1993:cap. 2).

A partir de 1978 inician sus reformas económicas con el desmantelamiento de las comunas en la agricultura, lo cual originó un cambio hacia la gestión familiar de explotación, mas no de propiedad, conformando mercados libres de productos agrarios, pero simultáneamente con mercados cautivos. Esto generó un impresionante aumento de la producción agraria, con diversificación productiva y notables desplazamientos de mano de obra desde las zonas rurales hacia las ciudades, lo que aportaría suficiente fuerza de trabajo para una industrialización acelerada. Sin embargo, las implicaciones de esos movimientos dieron lugar a una fragmentación de las explotaciones que afectaría a las infraestructuras y la inversión, empeoraría la condición de los grupos más vulnerables (pobres y ancianos) y provocaría un deterioro de las relaciones de intercambio agrícola (precios recibidos/ precios pagados). Sus grandes volúmenes de exportaciones no se han obtenido solamente por la liberalización de su comercio, sino por la intermediación de Hong Kong, pues gracias a ello, aproximadamente 53\% de las reexportaciones, entre 1988 y 1998, se hicieron por ese puerto. Durante la década de los años noventa las ganancias por servicios de intermediación proporcionados por Hong Kong son equivalentes a 16\% del valor de los bienes que China exporta por ese puerto y oscila entre 10 y $21 \%$ del valor de las exportaciones de

1 Acerca de las variaciones en remuneraciones y productividad del trabajo en la industria manufactu rera entre 1994 y 1999, véase Isabel Rueda Piero, "El Programa de Política Industrial y Comercio Exterior, y las empresas manufactureras en México. Algunas alternativas", en José Luis Calva (coordinador) Política económica para el desarrollo sostenido con equidad, México, IIEC UNAM,vol. 2, 2002, p. 96, Cuadro 5). 
bienes manufactureros (Feenstra, Hanson y Lin, 2002:4), cuyas cifras en 1998 eran alrededor de 100 mil millones de dólares, representando 16 mil millones de dólares por concepto de intermediación, sobre precio que se traslada a los consumidores mundiales y que puede asimilarse por los bajos precios. Se crean las zonas económicas especiales, áreas geográficas capitalistas, lejanas a Pekín y próximas a regiones (internacionales) en expansión, como Hong Kong y Taiwán, con la intención de que se conviertan en una especie de áreas francas y que repercutan positivamente al interior de la China continental.

El ingreso de China a la omc, con el apoyo de Estados Unidos a mediados de la década de los noventa, ${ }^{2}$ significó el ingreso de $22 \%$ de la población mundial; como productores y consumidores establecen un marco lleno de posibilidades, aunque no exento de riesgos, pues al mismo tiempo China tiene 300 millones de personas que viven en la miseria absoluta.

\section{Diferencias socioeconómicas de ambos países}

Las diferencias culturales de México y China son latentes; con bases ideológicas antagónicas, ambos países son considerados los dos grandes contendientes por la inversión estadounidense, principalmente de carácter maquilador. Estas diferencias se revelan en el contraste de los principales indicadores sociales y económicos durante la última década del siglo Xx. Incluso, al interior de China, existen grandes diferencias que es necesario destacar, no sólo en el plano de los indicadores socioeconómicos, sino también en el comercio exterior. Dentro de esos indicadores se puede apreciar que el crecimiento económico establecido por el incremento anual del PIB en México es de 3.5\% y no ha sufrido cambios sustanciales, mientras que en China, tanto dentro de los puertos comerciales de Macau y Hong Kong como en China continental, se aprecia una destacada desaceleración para finales de la década (véase Cuadro 1). Pese a ello, en esta última el crecimiento fue de más de $8 \%$ y ambos puertos comerciales, Macau y Hong Kong, poseen niveles de PIB per capita 23 y 32 veces en relación con el nivel que se registra en China continental, mientras que respecto de México, estos dos puertos tienen niveles de PIB per capita equivalente a 4.6 y 6.6 veces, respectivamente.

El valor agregado industrial chino continental alcanzó casi el doble del mexicano y de la inversión interna y extranjera directa. Comparando la producción y exportación de bienes con alto contenido tecnológico, los niveles son similares en ambos países, pero sobresale el puerto de Hong Kong como la principal salida de la producción china. Ello se comprueba al observar que sus exportaciones equivalen a $140 \%$ del PIB, lo que muestra claramente las reexportaciones efectuadas desde dicho puerto. También la proporción de valor agregado de maquinaria y equipo de transporte respecto de las manufacturas es

2 El 11 de diciembre de 2001 China se convirtió en integrante formal de la Organización Mundial de Comercio (OMC).

\section{DeSarrollo}


cercana en ambos países, pero tanto los gastos en tecnología para la información y las comunicaciones como proporción del PIB y la generación de estudiantes de ciencia e ingeniería frente al total de estudiantes, son levemente mayores en China y mucho más grande la diferencia con técnicos en I\&D por cada millón de personas, donde supera a México por más del doble de técnicos, científicos e ingenieros en I\&D por cada millón de personas.

La dependencia de la producción de combustible proveniente del mercado internacional para contribuir al proceso de industrialización es mayor en aquel país que en el nuestro; de allí que las importaciones de combustible sea aproximadamente el doble que la proporción que pesa dentro del PIB mexicano. Pese a que el proceso de urbanización de China se puede catalogar como reciente, las condiciones a las que enfrentaron los países latinoamericanos y, específicamente, México son completamente distintas. La distribución de la renta parece haber mejorado durante la primera fase de la reforma (1979-1984) como resultado de las modificaciones en la agricultura, así como hasta 1990, a causa de la intensidad en factor trabajo del crecimiento industrial, para posteriormente empeorar (Khan y Riskin, 1998:221-253). El índice de desarrollo humano (IDH), calculado por el PNUD, aumentó de 0.475 (el nivel actual de Myanmar o Ghana) en 1980 a 0.644 en 1992, pero disminuyó a 0.626 en 1994 (PNUD, 1997, Cuadro 5).

Hay mayor vinculación de la mujer en las actividades productivas chinas, aunado a su capacidad científica y tecnológica — que sirve de base de construcción social, frente al momento histórico actual en que las barreras arancelarias se derrumban y el mercado internacional es, más que nunca, un artífice de la construcción de las economías de las naciones-; China obtiene, entonces, la oportunidad de ganarse no sólo un lugar en el contexto internacional, sino de aportar esquemas exitosos que también han llevado a otros países asiáticos a convertirse en líderes tecnológicos, productivos y comerciales.

Aún quedan serias dudas acerca de la capacidad de inclusión social que pueda desarrollar este país, debido a su todavía alta ruralidad, pues cerca de $70 \%$ de la población se encuentra vinculada a actividades del campo y el total aún registra tasas de crecimiento demográficas de $2.7 \%$ anual en China continental, frente a $1.7 \%$ en México.

\section{Evaluación de las ventajas comerciales de México y China}

La comparación de China y México en cuanto a la capacidad exportadora, la dirección de sus exportaciones y la demanda internacional de sus productos muestra el nivel de competitividad que ambos países tienen en el concierto mundial. Dentro del análisis que se pretende realizar, se desagrega la información en tres regiones: los puertos de Macau y Hong Kong, y China continental. Esta presentación expone directamente el grado de reexportaciones de China, principalmente de Hong Kong, que se ha convertido en su ventanilla comercial. Con base en información del International Trade Centre de UNCTAD/ wTO (2000), se puede apreciar que, respecto del destino de las exportaciones, se advierten

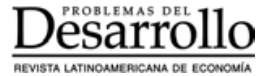




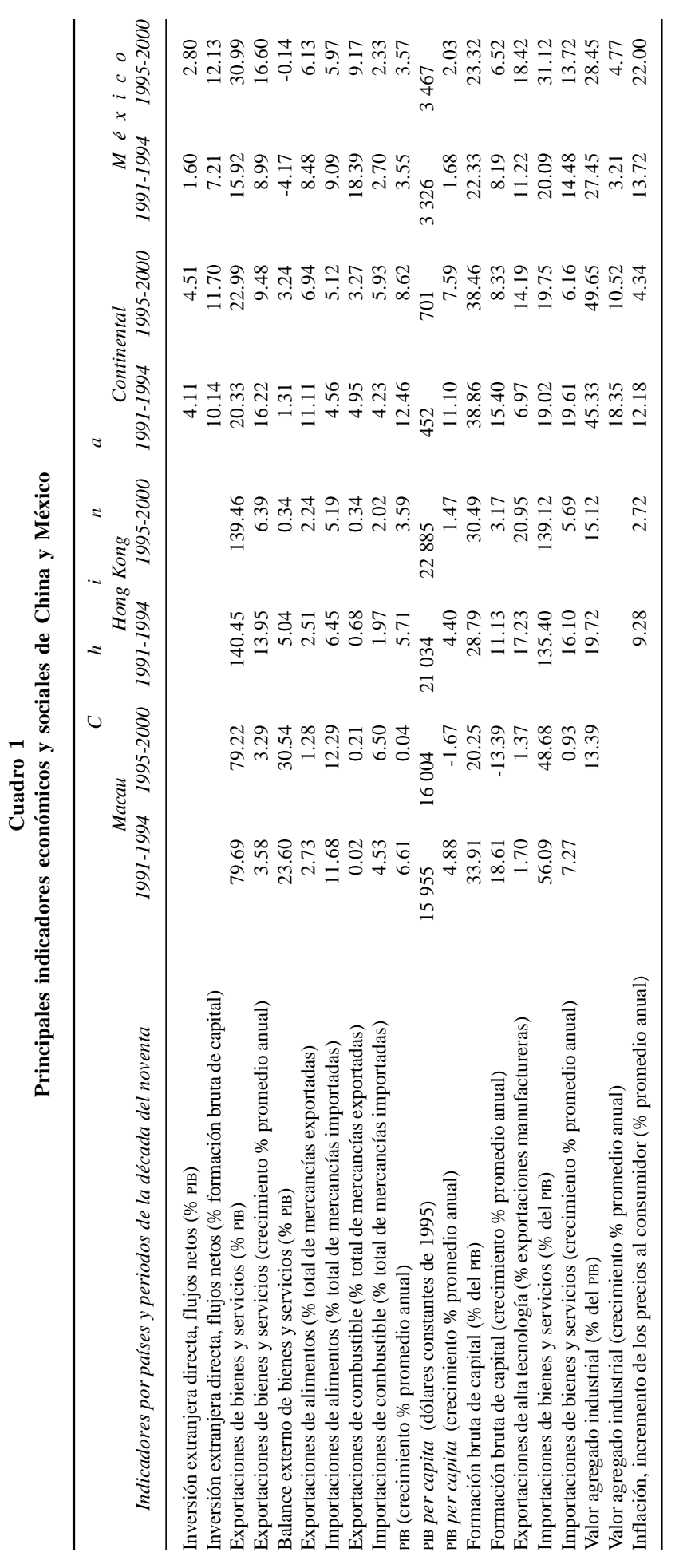




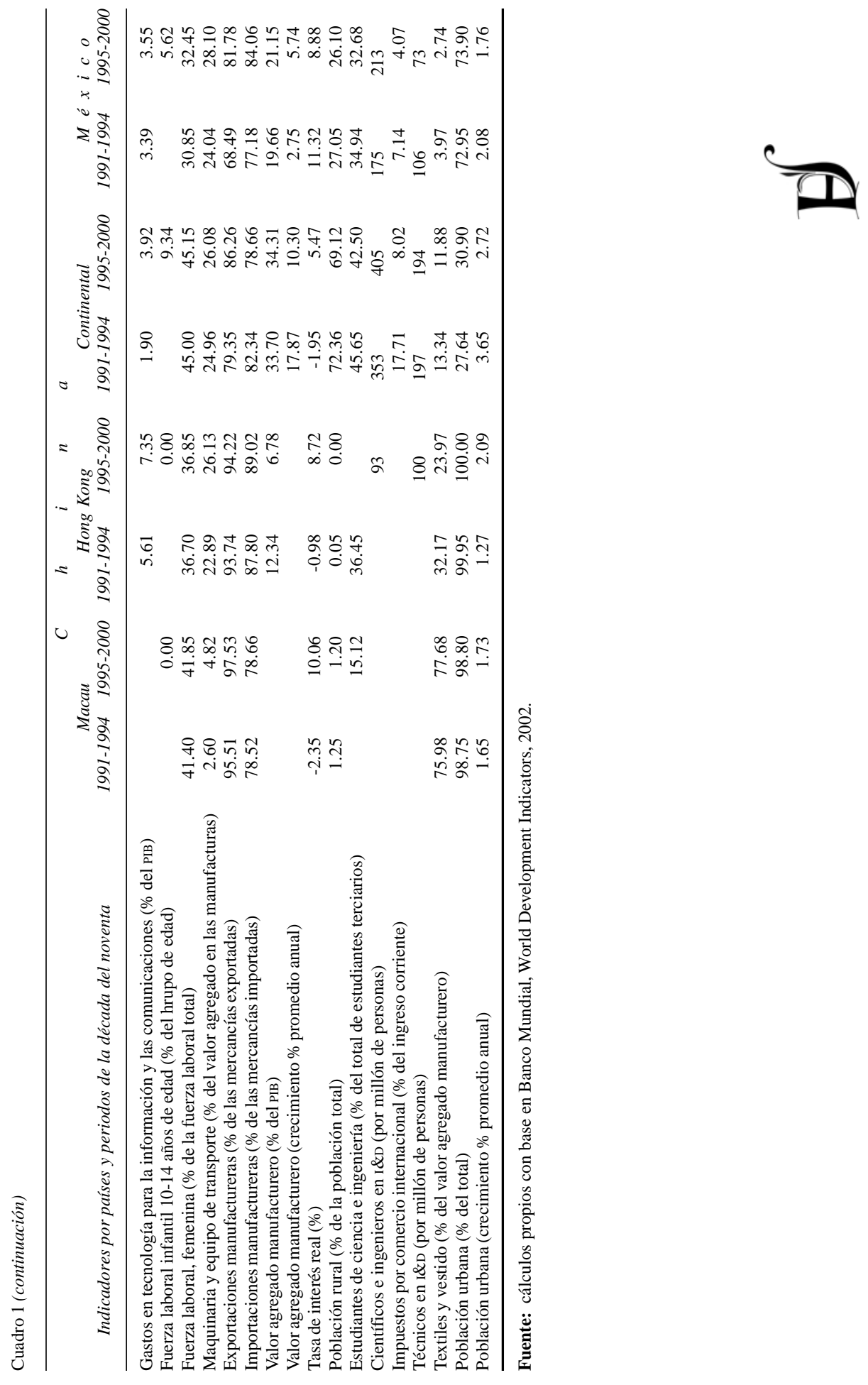


JORGE ENRIQUE HORBATH

Cuadro 2

Distribución de las exportaciones por país destino, 2000

\begin{tabular}{lrlrllllr}
\hline \multicolumn{2}{c}{ Hong Kong } & \multicolumn{2}{c}{ Macau } & \multicolumn{2}{c}{ China } & \multicolumn{2}{c}{ México } \\
País importador & $\%$ & País importador & $\%$ & País importador & $\%$ & País importador & $\%$ \\
\hline China & 34.33 & Estados Unidos & 59.43 & Estados Unidos & 36.41 & Estados Unidos 86.80 \\
Estados Unidos & 32.08 & Alemania & 9.53 & Japón & 19.65 & Canadá & 4.22 \\
Inglaterra & 6.03 & Inglaterra & 7.80 & Alemania & 6.02 & Alemania & 1.13 \\
Alemania & 3.97 & Francia & 5.29 & República de Corea & 4.39 & Japón & 0.89 \\
Países Bajos & 3.11 & Países Bajos & 4.01 & Francia & 3.19 & Reino Unido & 0.50 \\
Japón & 2.76 & Canadá & 2.33 & Reino Unido & 2.85 & Brasil & 0.49 \\
Canadá & 2.08 & Hong Kong & 2.05 & Canadá & 2.48 & Venezuela & 0.41 \\
Singapur & 1.90 & Italia & 1.26 & Países Bajos & 2.40 & Chile & 0.40 \\
Corea & 1.26 & España & 1.18 & Italia & 2.28 & Guatemala & 0.37 \\
Filipinas & 1.24 & Dinamarca & 1.13 & Australia & 1.93 & Francia & 0.36 \\
Acumulado & 88.77 & Acumulado & 94.01 & Acumulado & 80.61 & Acumulado & 95.56 \\
\hline
\end{tabular}

Fuente: unctad/wto (2000).

tres fenómenos: primero, que un porcentaje considerable de sus exportaciones están dirigidas al mercado estadounidense, primordialmente en el caso de México (86.8\%, véase Cuadro 2); segundo, que este último, a diferencia de China, presenta una alta concentración comercial en un solo mercado; y tercero, como ya se mencionó, que el puerto de Hong Kong hace el papel de intermediación comercial de cerca de 35\% del comercio entre la demanda internacional y China continental.

Los datos de exportaciones de Hong Kong y Macau también muestran una participación alta en el mercado estadounidense y menor diversificación de mercados —a diferencia de China-, principalmente Macau, que concentra por lo menos tres cuartas partes de sus exportaciones en tres países. Las cifras de importación de Estados Unidos, durante 1999-2000, señalan que sus principales proveedores eran México y China —en ese orden hasta 2000 que, en conjunto, proporcionaron 53.9\% del valor de las mercancías (véase Cuadro 3).

En el análisis de flujos comerciales, el indicador de la ventaja comparativa tiene como objetivo medir la especialización ${ }^{3}$ de México y China en cada uno de los sectores productivos. De acuerdo con la ecuación, la ventaja comparativa revelada es estandarizada por el país exportador considerado.

$$
R C A_{i c l}^{t}=\frac{1000}{\left(X_{i}^{t} \ldots+M_{i}^{t}\right)} *\left[\left(X_{i c l}^{t}-M_{i c l}^{t}\right)-\left(X_{i}^{t}-M_{i}^{t}\right) * \frac{\left(X_{i c l}^{t} \ldots+M_{i c l}^{t}\right)}{\left(X_{i}^{t} \ldots+M_{i}^{t}\right)}\right]
$$

3 El índice mide la ventaja comparativa revelada del país en exportaciones según la fórmula de Balassa. El índice compara la proporción en exportaciones nacionales de un sector dado respecto de dicho sector en las exportaciones del mundo. Los valores sobre 1 indican que el país está especializado en el sector en revisión. El cuadro demuestra la posición de dichos índices en los países: la posición 1 indicaría que el país tiene el índice más alto en el mundo para el sector en revisión.

\section{Desarrollo}


Cuadro 3

Principales países importadores

de mercancías a Estados Unidos, 2000

\begin{tabular}{lrr}
\hline Origen de la importación & Miles de dólares & $\%$ \\
\hline México & 113888223 & 31.82 \\
China & 79102876 & 22.10 \\
Corea & 35468533 & 9.91 \\
Malasia & 22039425 & 6.16 \\
Tailandia & 14957563 & 4.18 \\
Filipinas & 12564888 & 3.50 \\
Brasil & 11777581 & 3.30 \\
Indonesia & 9115481 & 2.55 \\
India & 6981641 & 1.95 \\
Rusia & 5299553 & 1.48 \\
85 países restantes & 46760843 & 13.5 \\
\hline
\end{tabular}

Fuente: UNCTAD/WTO (2000).

En la cual $X_{i}^{t}$ y $M_{i}^{t}$ y $X_{i c l}^{t}$ y $M_{i c l}^{t}$ son las exportaciones e importaciones del país $i$ en el año $t$ respectivamente, $\mathrm{y}$

$\left(X_{i c l}^{t}-M_{i c l}^{t}\right)$ son las exportaciones e importaciones de productos pertenecientes al cluster $c l$ del país $i$ en el año $t$ respectivamente,

$\frac{\left(X_{i c l}^{t} \ldots+M_{i c l}^{t}\right)}{\left(X_{i}^{t} \ldots+M_{i}^{t}\right)} \begin{aligned} & \text { es el desbalance observado del comercio del país } i \text { para el } c l u s t e r ~ c l \text { en el } \\ & \text { año } t\end{aligned}$ $\frac{\left(X_{i c l}^{t} \ldots+M_{i c l}^{t}\right)}{\left(X^{t} \ldots+M^{t}\right)}$ es el peso del cluster en las exportaciones del país $i$ en el año $t$. $\left(X_{i}^{t} \ldots+M_{i}^{t}\right)$ $\left(X_{i}^{t}-M_{i}^{t}\right) * \frac{\left(X_{i c l}^{t} \ldots+M_{i c l}^{t}\right)}{\left(X_{i}^{t} \ldots+M_{i}^{t}\right)}$ es el desbalance teórico del país $i$ para el cluster $c l$ en el año $t$.

La ventaja comparativa revelada (RCA, por sus siglas en inglés) muestra cómo un país dado asigna sus recursos en sus diferentes industrias (con el supuesto del comercio equilibrado). La finalidad de este índice es identificar para cada país los sectores con los niveles más altos de especialización, más que hacer una comparación entre países.

China tiene ventajas comparativas reveladas en la mitad de los sectores revisados, lo cual implica que en éstos se da un alto grado de especialización. La posición alcanzada por la miscelánea manufacturera le coloca entre los diez primeros lugares.

Para Hong Kong los sectores de miscelánea, vestido, componentes electrónicos y textiles tienen índices de ventajas comparativas mayores que 1, además de que se posicionan en lugares importantes en el nivel mundial. En el caso de Macau, sólo vestidos y productos de cuero tienen índices mayores a la unidad; en el sector de vestimenta ocupa el índice 
JORGE ENRIQUE HORBATH

Cuadro 4

Ventaja comparativa revelada de México y China, 2000

\begin{tabular}{|c|c|c|c|c|c|c|c|c|}
\hline \multirow[t]{2}{*}{ Sector/producto } & \multicolumn{2}{|c|}{ México } & \multicolumn{2}{|c|}{ Hong Kong } & \multicolumn{2}{|c|}{ Macau } & \multirow{2}{*}{\multicolumn{2}{|c|}{$\begin{array}{c}\text { China } \\
\text { Posición Índice }\end{array}$}} \\
\hline & Posición & Índice & Posición & Índice & Posición & Índice & & \\
\hline $\begin{array}{l}\text { Computadoras, telecomunicacio } \\
\text { y electrónica de consumidor }\end{array}$ & es & 1.96 & 28 & 0.58 & & & 13 & 1.72 \\
\hline Componentes Electrónicos & 12 & 1.56 & 13 & 1.46 & 73 & 0.16 & 22 & 1.05 \\
\hline Equipo de transporte & 13 & 1.43 & & & & & 48 & 0.27 \\
\hline Maquinaria no electrónica & 27 & 0.75 & 72 & 0.21 & & & 40 & 0.49 \\
\hline Miscelánea & 28 & 1.10 & 5 & 1.97 & 90 & 0.27 & 9 & 1.73 \\
\hline Vestido & 58 & 1.52 & 10 & 14.16 & 1 & 26.37 & 30 & 4.16 \\
\hline Textiles & 73 & 0.52 & 21 & 2.08 & 83 & 0.42 & 12 & 2.48 \\
\hline Manufactura básica & 74 & 0.74 & 108 & 0.22 & 124 & 0.09 & 54 & 1.03 \\
\hline Productos de cuero & 85 & 0.34 & & & 20 & 3.44 & 13 & 4.53 \\
\hline Minerales & 85 & 0.67 & 126 & 0.13 & & & 109 & 0.27 \\
\hline Químicos & 86 & 0.35 & 89 & 0.30 & 118 & 0.07 & 75 & 0.50 \\
\hline Productos de madera & 104 & 0.27 & 91 & 0.44 & & & 89 & 0.46 \\
\hline Alimentos procesados & 112 & 0.51 & 115 & 0.44 & 130 & 0.23 & 103 & 0.60 \\
\hline Alimentos frescos & 123 & 0.77 & & & & & 121 & 0.83 \\
\hline
\end{tabular}

Fuente: UNCTAD/wTo (2000).

más alto de la especialización en el mundo. Ahora bien, es necesario matizar estos resultados, porque se debe recordar que Hong Kong y Macau son puertos y su comercio se basa en las reexportaciones desde China continental; esos indicadores no son directamente suyos, pero permiten reconocer sus ventajas en esos aspectos. En el caso de México, excepto en el sector de vestido, ocupa posiciones importantes en los pocos sectores que tienen índices de ventajas comparativas reveladas superiores a 1 .

\section{Competidores en el mercado estadounidense}

Después de observar las reformas económicas de México y China, y sus características socioeconómicas, además de realizar una disección de la capacidad comercial en el mercado internacional, se expondrán sus principales diferencias dentro del mercado estadounidense y la manera en que ambas naciones se disputan las preferencias del capital, representado por las inversiones de las empresas maquiladoras.

\section{Desempeño comercial de México y China en el mercado estadounidense}

El traumático proceso de crecimiento económico interrumpido de México ha estado acompañado por reiteradas crisis, ajustes económicos y la entrada en vigor del tratado de libre comercio con Canadá y Estados Unidos, el cual parece no tener claridad en cuanto a resultados favorables para la población y el mercado interno. En tanto, China parece haber preparado con antelación y visión de largo plazo el abordaje de los mercados internacionales, al ingresar a la Organización Mundial de Comercio (OMC), con el respaldo de 
Estados Unidos. Una evidencia de ello se encuentra en la comparación de las importaciones y exportaciones de Estados Unidos desde y hacia México y China, desde 1985 hasta 2003.

La comparación resulta favorable para el país asiático, pues hasta 2003 nuestro país fue desplazado como principal socio comercial de Estados Unidos. Para México, el crecimiento promedio anual de las exportaciones a aquel mercado ha sido de $1.54 \%$, cifra de la misma magnitud para las importaciones que México hace desde Estados Unidos. Mientras que China logró elevar sus exportaciones anuales a Estados Unidos a una tasa de 2.66\%, y sus importaciones por productos estadounidenses se incrementaron a un ritmo de $1.68 \%$ anual. Al tomar esos dos datos para estimar la elasticidad de las exportaciones a Estados Unidos de las importaciones desde este país, se obtiene que México tiene una elasticidad de 1, o sea, que por cada punto porcentual de incremento de las exportaciones, las importaciones aumenta en la misma magnitud. Para China, el valor de esa elasticidad es de 1.57, por lo cual por cada incremento en un punto porcentual en las importaciones desde Estados Unidos, las exportaciones hacia este socio comercial se elevan en 1.57 puntos porcentuales.

Si se observa la Gráfica 1, en la cual se presentan las cuatro variables mencionadas, una vez que se desestacionalizaron para corregir los sesgos de la información mensual, se puede apreciar claramente que en el comercio desde China con Estados Unidos, a partir de la segunda mitad de los años ochenta —específicamente en 1986, cuando el saldo comercial era nulo- se inicia un crecimiento más acelerado de las exportaciones respecto de sus importaciones desde Estados Unidos. Ello le significaría un saldo favorable de 1.78 millones de dólares mensuales para junio de 2003, mientras que el saldo comercial mexicano con Estados Unidos llegó a 0.37 millones de dólares y, al parecer, solamente hasta la mitad de los noventa se logró que el saldo fuera favorable. Las cifras desestacionalizadas ubican en febrero como el momento histórico en el cual China arrebató la hegemonía mexicana como socio comercial de Estados Unidos; no obstante, sin efectuar la desestacionalización, los datos muestran que desde agosto de 2002 - y con excepción de octubre del mismo año y los meses de febrero y marzo de 2003-, China había desplazado a México del primer lugar en ese mercado.

El peso relativo de los productos mexicanos dentro de la demanda estadounidense muestra alta concentración, mientras que los chinos han logrado establecer no sólo mayor diversificación, sino también mayor posicionamiento, pues sus productos alcanzan pesos importantes: quince logran tener pesos superiores a 30\%, seis de ellos superan $50 \%$ y, en ese mismo rango, solamente seis productos mexicanos logran este nivel y ninguno de ellos llega a representar la mitad de la demanda estadounidense por productos importados. Incluso, si se amplía la cota mínima en el rango de participación a $20 \%$, se aprecia una baja participación de los productos mexicanos, mientras que los chinos muestran una participación activa: entre 20 y $30 \%$ se encuentran diez productos chinos donde el peso de los 


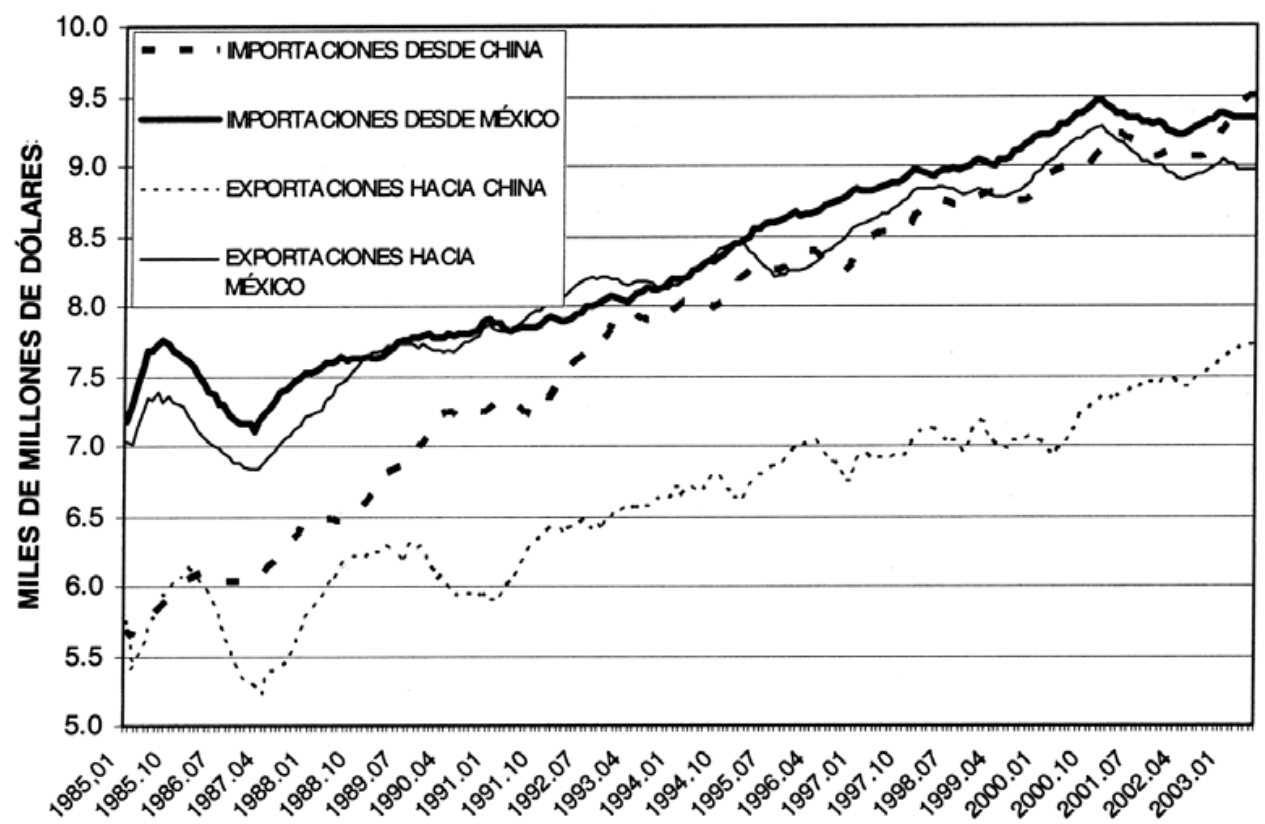

Gráfica 1. Importaciones y exportaciones mensuales de Estados Unidos desde y hacia China y México: 19852003, series desetacionalizadas.

Fuente: $\quad$ us Census Bureau, Foreign Trade Eivision, Data Dissemination Branch, Washington, DC 20233.

mexicanos no alcanza 15\%; en ese rango solamente hay cuatro productos mexicanos. La gran mayoría de éstos sólo logra un peso relativo de menos del $15 \%$.

En este aspecto, el análisis busca destacar la importancia del producto mexicano en el mercado estadounidense de ese rubro, pero no en el total. Ello sesgaría definitivamente la perspectiva de competencia, pues en un ordenamiento por peso relativo en el total de las importaciones estadounidenses resultan guarismos muy pequeños, mientras que un ordenamiento por peso relativo en el total de las exportaciones mexicanas hacia Estados Unidos no reflejaría tampoco el nivel de competitividad del producto. Por ello, al observar el Cuadro 5, se puede apreciar los veinte productos de mayor importancia en el mercado estadounidense, identificados así por el peso relativo promedio entre 1998 y 2002 en su demanda desde ese país. En este cuadro se construyó adicionalmente el crecimiento medio anual en el mismo periodo y se contrastó cada uno de esos productos con el comportamiento del mismo proveniente de China.

Lo principal corresponde a vegetales y preparaciones de éstos con un cubrimiento de 46.2\% del mercado estadounidense; su crecimiento alcanza a ser de $3.1 \%$ anual y parece que no es un producto que pueda ser desplazado fácilmente por China, pues el peso del mismo es de 3.4\% y obtiene un incremento, aunque levemente mayor; no muestra peligro actual para México. Pero el segundo producto, receptores y aparatos de televisión y video, corre el riesgo de ser desplazado, pues China tiene una participación de $16 \%$ y aumento

\section{DeSarrollo}


BALANCE DE LA COMPETENCIA ENTRE MÉXICOY CHINA EN EL MERCADO

Cuadro 5

Comparación de veinte principales productos mexicanos en el mercado estadounidense respecto de los productos chinos entre 1998 y 2002, según mayor participación

\begin{tabular}{|c|c|c|c|c|c|}
\hline \multirow{2}{*}{\multicolumn{2}{|c|}{ Códigos }} & \multicolumn{2}{|c|}{ China } & \multicolumn{2}{|c|}{ México } \\
\hline & & $\begin{array}{l}\text { \% Impor- } \\
\text { taciones } \\
\text { de EU }\end{array}$ & $\begin{array}{c}\text { Tasa de } \\
\text { crec. } \% \\
\text { anual }\end{array}$ & $\begin{array}{c}\text { \% Impor- } \\
\text { taciones } \\
\text { de EU }\end{array}$ & $\begin{array}{r}\text { Tasa de } \\
\text { crec. \% } \\
\text { anual }\end{array}$ \\
\hline 1 & (00130) Verduras y preparaciones & 3.45 & 5.17 & 46.21 & 3.10 \\
\hline 2 & (41200) Receptores de la televisión, VCR y otros videos & 15.94 & 40.62 & 36.66 & 3.18 \\
\hline 3 & (30100) Complemento y ensamblado & 0.13 & 42.84 & 33.17 & 18.95 \\
\hline 4 & (30230) Otras partes y accesorios & 4.78 & 14.27 & 32.87 & 9.60 \\
\hline 5 & (20000) Generadores, transformadores y accesorios & 13.93 & 5.62 & 30.66 & 2.25 \\
\hline 6 & (30110) Cuerpos y chasis para los camiones y autobúses & 0.02 & 639.58 & 30.28 & -3.11 \\
\hline 7 & (21160) Instrumentos de medición, testeo y control & 4.76 & 15.08 & 23.92 & 12.14 \\
\hline & (21300) Computadoras & 34.00 & 39.22 & 22.73 & 22.58 \\
\hline & (20005) Aparatos eléctricos y partes & 19.38 & 6.60 & 22.65 & 6.36 \\
\hline & (41030) Aparatos para el hogar y la cocina & 35.36 & 19.52 & 21.10 & 15.17 \\
\hline & (22100) Equipo de transporte ferroviario & 1.61 & 3.04 & 19.15 & -2.97 \\
\hline & $2(30200)$ Artefactos y partes & 1.61 & 15.97 & 18.62 & 5.53 \\
\hline & 3 (00120) Frutas y preparaciones, incluyendo congelados & 2.47 & 20.84 & 18.52 & 1.80 \\
\hline & 4 (00190) Vino y productos relacionados & 0.16 & 6.84 & 17.27 & 16.18 \\
\hline & 5 (13100) Vasos, platos, cubiertos (excluye móviles) & 22.12 & 22.88 & 16.33 & 11.26 \\
\hline & 5 (21400) Equipo de Telecomunicaciones & 13.87 & 21.01 & 15.24 & 20.90 \\
\hline & 7 (00000) Café verde & 0.03 & 35.40 & 14.95 & -19.18 \\
\hline & 3 (40000) Prendas de algodón y géneros para el hogar & 17.46 & 3.30 & 14.90 & 5.95 \\
\hline & (15200) Figuras de metal terminado y manuf., excepto acerc & ro 16.15 & 10.44 & 13.82 & 11.80 \\
\hline & (12140) Otros materiales (cabello, materiales desechos) & 17.72 & 12.70 & 13.75 & 18.10 \\
\hline
\end{tabular}

Fuente: cálculos propios con base en us Census Bureau, Foreign Trade Division, Data Dissemination Branch, Washington, DC.

anual de $40.6 \%$, en pocos años puede desplazar $37 \%$ mexicano que se encuentra creciendo a 3.2\% anual. Otros, como las computadoras, ya han sido desplazados por los chinos; su participación supera en 12 puntos porcentuales a la realizada por México y su velocidad de crecimiento anual casi sobrepasa 20 puntos. Ahora bien, en un ordenamiento de mayor a menor por el crecimiento medio anual, se obtiene que los principales productos con más crecimiento se encuentra vinculados a los recursos energéticos y derivados del crudo, pero con niveles tan altos que reflejan volatilidad en la demanda (véase Cuadro 6).

Pero esta volatilidad parece no ser la constate directa en el caso del crudo importado por Estados Unidos, pues el abastecimiento de ese producto representa una garantía para su maquinaria industrial. Es por ello que el crudo mexicano ha logrado cubrir a más de $13 \%$ de la demanda estadounidense, con un crecimiento medio de $28 \%$ anual.

De esta manera, si tomamos en cuenta que el grado de desplazamiento de los productos mexicanos por chinos se basa en la relación entre el crecimiento medio de estos últimos respecto de los primeros, al construir una gráfica de dispersión con ese indicador, se puede apreciar la magnitud de dicho desplazamiento de acuerdo con los cuadrantes de la 
Cuadro 6

Comparación de los veinte principales productos mexicanos en el mercado estadounidense respecto de los productos chinos entre 1998 y 2002, según mayor crecimiento

\begin{tabular}{|c|c|c|c|c|}
\hline \multirow[b]{2}{*}{ Código } & \multicolumn{2}{|r|}{ China } & \multicolumn{2}{|c|}{ México } \\
\hline & $\begin{array}{c}\text { \% Impor- } \\
\text { taciones } \\
\quad \text { de EU }\end{array}$ & $\begin{array}{c}\text { Tasa de } \\
\text { crec. } \% \\
\text { anual }\end{array}$ & $\begin{array}{c}\% \text { Impor- } \\
\text { taciones } \\
\text { de EU }\end{array}$ & $\begin{array}{c}\text { Tasa de } \\
\text { crec. \% } \\
\text { anual }\end{array}$ \\
\hline 1 (10110) Gas natural & 0.00 & & 0.06 & 28563 \\
\hline 2 (10030) Gases licuados del petróleo & 0.00 & 138.78 & 2.22 & 233.60 \\
\hline 3 (21150) Maquinaria para pulpa y papel & 2.07 & 14.90 & 0.26 & 169.28 \\
\hline 4 (50000) Aviones militares y sus partes & 0.63 & -14.59 & 5.81 & 135.99 \\
\hline 5 (41300) Monedas numismáticas & 3.60 & -9.14 & 2.27 & 96.41 \\
\hline 6 (00010) Cacao y frijoles & 0.01 & -100.00 & 0.77 & 84.14 \\
\hline 7 (10010) Aceite de combustible & 0.16 & 465275 & 0.82 & 76.87 \\
\hline 8 (21600) Pruebas de laboratorio e instrumentos de control & 6.50 & 12.94 & 1.27 & 74.62 \\
\hline 9 (00020) Azucar de caña y de remolacha & 0.94 & -9.89 & 7.48 & 67.13 \\
\hline 10 (21010) Equipo especial para minería y proceso de aceite & 2.74 & 25.60 & 0.31 & 63.03 \\
\hline 11 (41110) Botes de placer y motores & 8.16 & 19.89 & 3.46 & 56.86 \\
\hline 12 (30210) Cuerpos y chasis para automóviles de pasajeros & 2.12 & 182.94 & 4.50 & 47.20 \\
\hline 13 (10020) Otros productos del petróleo & 1.54 & 35.00 & 4.38 & 31.44 \\
\hline 14 (01010) Bebidas alcohólicas, excepto vino y otros & 0.08 & 10.03 & 10.97 & 30.31 \\
\hline 15 (42100) Gemas de diamantes, en bruto o cortados & 2.06 & 10.17 & 0.09 & 28.65 \\
\hline 16 (22010) Partes de aviones civiles & 1.41 & 14.26 & 1.77 & 28.64 \\
\hline 17 (10000) Crudo & 0.30 & 87.38 & 13.52 & 28.04 \\
\hline 18 (22000) Aviones civiles, completo-todos los tipos & 0.02 & 1181.01 & 0.00 & 25.41 \\
\hline 19 (11110) Papel y productos de papel & 1.91 & 22.87 & 1.46 & 23.85 \\
\hline 20 (21610) Otros equipos científicos, médicos y para hospital & 8.46 & 14.63 & 11.53 & 23.47 \\
\hline
\end{tabular}

Fuente: cálculos propios con base en us Census Bureau, Foreign Trade Division, Data Dissemination Branch, Washington, DC.

misma gráfica. En efecto, el cuadrante I muestra una relación de productos en donde el crecimiento es positivo en ambos casos, por lo cual puede ser que si la demanda interna estadounidense se incrementa, ambos países estén desplazando a competidores diferentes a ellos. Éste parece ser el caso actual, pues en la Gráfica 2 se logra identificar que la mayor parte de los productos se encuentran en ese cuadrante.

Siguiendo la lógica cartesiana, el cuadrante II estaría mostrando aquellos productos chinos que crecen a costa del decrecimiento de los mexicanos, mientras que su contraparte en el cuadrante Iv mostraría la ganancia de mercado por parte de México al desplazar a los chinos. En un balance entre los dos cuadrantes, claramente se logra apreciar que hay más productos chinos desplazando a los mexicanos que la dirección inversa.

Finalmente, el cuadrante III señala el grado de desplazamiento de productos mexicanos y chinos por la entrada de nuevos o porque su contracción es por la desaceleración o caída de la demanda interna por productos externos. En este cuadrante existen pocos productos, por lo cual parece que ambos países no padecen de esa vulnerabilidad. Como conclusión se puede afirmar que México perdió aproximadamente 1512 millones de dólares anuales 


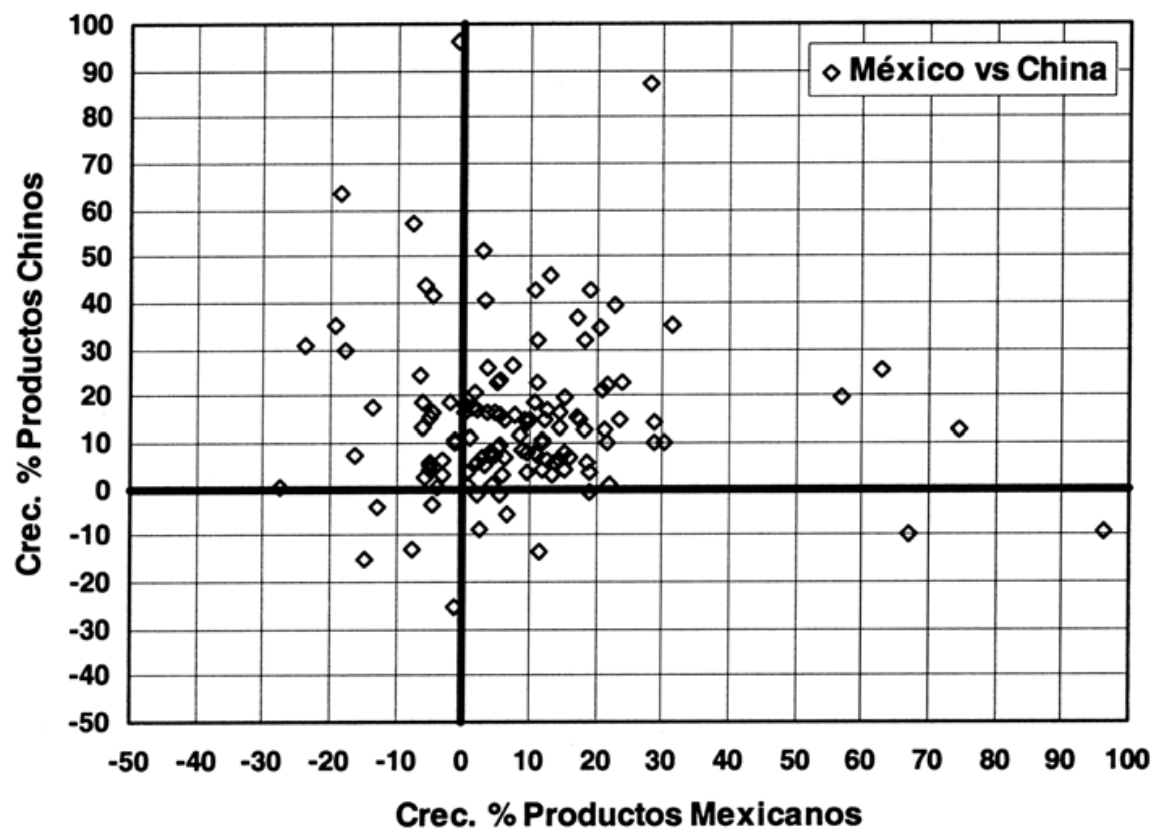

Gráfica 2. Relación entre el crecimiento de la demanda de productos mexicanos y chinos en Estados Unidos, 1998-2002.

Fuente: $\quad$ us Census Bureau, Foreign Trade Division, Data Dissemination Branch,Washington, DC 20233.

entre 1998 y 2002, lo que equivale a un monto cercano a los 7563 millones de dólares en cinco años, mientras que China logró colocar 13644 dólares adicionales en promedio al año, esto es, cerca 68224 millones de dólares en el periodo. Es decir, China no sólo desplazó a México, sino también a otros competidores; logró una ganancia de más de 6000 millones de dólares al desplazar a competidores diferentes a México. Sin embargo, aunque dicha pérdida no es una noticia agradable, nuestro país logró desplazar productos chinos, pues éstos sufrieron una caída estimada en 340 millones de dólares al año, lo cual significó un total de 1704 millones en los cinco años, mientras que México incrementó en 9472 millones anuales, lo que significaría un total de 47364 millones. Pero el saldo final en cuanto a incrementos, siguió siendo favorable para China: en México alcanzó a ser de 79029 millones de dólares anuales, esto es, 398147 millones en los cinco años, frente a la ganancia de China que fue de 404217 millones anuales, lo cual representó un total de 2021085 millones de dólares en los cinco años.

\section{China y México compitiendo por la maquila estadounidense}

Después de ver la estructura y forma de competencia entre México y China por el mercado estadounidense, este nivel de batalla comercial podría estar basado en la capacidad de ambos países para lograr atraer el capital de las maquiladoras de estadounidenses. Esta

\section{Desararrollo}


lucha comercial es bastante difícil de observar principalmente en cifras, pues el acceso a la información comercial de China es limitada, mientras que en el caso de México existe un desglose de las estadísticas de comercio dentro de esa actividad industrial (maquiladora).

La solución sería observar esos flujos comerciales desde el país demandante, Estados Unidos, pero dicho seguimiento en la actualidad es prácticamente nulo, pues con la entrada en vigor del TLCAN, la forma de registro de dichos flujos en el régimen de la maquila solamente tendrían vigencia poco tiempo. Su efecto en las estadísticas se apreció, pues la fracción arancelaria 9802 del sistema armonizado en el cual se registraban dichos flujos fue modificada, de tal forma que las importaciones desde México ya no se iban a registrar. Una consulta a dicha fracción arancelaria en 2001 permitió el acceso parcial pero suficiente a esa información, tanto para los agregados, como para los principales grupos de productos de la maquila en México.

Los datos muestran que en el régimen 9802, hasta 2000, el principal socio comercial de Estados Unidos era México, con un monto de 19429 millones de dólares, con una caída significativa respecto de 1999 cercana a $25 \%$ y cuyo contenido estadounidense alcanzaba a ser de $52 \%$ (véase Cuadro 7).

El ordenamiento de los países según el valor de las importaciones que realizaba Estados Unidos en este régimen mostró que China no se encontraba entre los diez primeros y que los montos que entraban a ese mercado por concepto de maquila estaban en cifras inferiores a los 1300 millones de dólares, lo cual no representaría una amenaza directa para México dentro de la actividad maquiladora. Pero al empezar a desagregar esta fracción

Cuadro 7

Total de importaciones a Estados Unidos en el régimen 9802 del sA (miles de dólares)

\begin{tabular}{|c|c|c|c|c|c|c|c|c|}
\hline \multirow[b]{2}{*}{ Países } & \multicolumn{2}{|c|}{ Importaciones } & otales & \multicolumn{3}{|c|}{ Contenido EU } & \multicolumn{2}{|c|}{$\%$ Contenido EU } \\
\hline & 1999 & 2000 & $\%$ Crec. & 1999 & 2000 & $\%$ Crec. & 1999 & 2000 \\
\hline México & 25875029 & 19429900 & -24.91 & 13927676 & 10271147 & -26.25 & 53.83 & 52.86 \\
\hline Japón & 15058216 & 17851266 & 18.55 & 575935 & 542994 & -5.72 & 3.82 & 3.04 \\
\hline Alemania & 11171668 & 9848654 & -11.84 & 155623 & 136905 & -12.03 & 1.39 & 1.39 \\
\hline República Dominican & a 2789322 & 2726664 & -2.25 & 1791339 & 1700066 & -5.10 & 64.22 & 62.35 \\
\hline Filipinas & 2331301 & 2098702 & -9.98 & 1136948 & 933069 & -17.93 & 48.77 & 44.46 \\
\hline Suecia & 1351778 & 2080042 & 53.87 & 60346 & 41694 & -30.91 & 4.46 & 2.00 \\
\hline Honduras & 1882012 & 1890338 & 0.44 & 1328843 & 1299539 & -2.21 & 70.61 & 68.75 \\
\hline Reino Unido & 1572986 & 1870321 & 18.90 & 250656 & 213309 & -14.90 & 15.94 & 11.40 \\
\hline Malasia & 2109056 & 1639294 & -22.27 & 998048 & 884820 & -11.34 & 47.32 & 53.98 \\
\hline Corea & 2002321 & 1377973 & -31.18 & 1042176 & 753049 & -27.74 & 52.05 & 54.65 \\
\hline Resto (134 países) & 12183149 & 10541033 & -13.48 & 4090354 & 3762409 & -8.02 & 33.57 & 35.69 \\
\hline Total & 78326838 & 71354187 & -8.90 & 25357944 & 20539001 & -19.00 & 32.37 & 28.78 \\
\hline
\end{tabular}

Fuente: cálculos propios con base en información suministrada por la Comisión de Comercio Internacional de Estados Unidos. 


\begin{tabular}{|c|c|c|c|c|c|c|c|c|}
\hline \multirow[b]{3}{*}{ Países } & \multicolumn{6}{|c|}{$\begin{array}{c}\text { Cuadro } 8 \\
\text { Importaciones a Estados Unidos con el régimen } 9802 \text { del sA } \\
\text { Aparatos de televisión (excepto receptores y monitores), } \\
\text { incluidas cámaras y cables para aparatos } \\
\text { (miles de dólares) }\end{array}$} & & \\
\hline & \multicolumn{2}{|c|}{ Importaciones } & \multirow{2}{*}{$\begin{array}{l}\text { to ta les } \\
\quad \% \text { Crec. }\end{array}$} & \multicolumn{2}{|c|}{ Contenido } & \multirow{2}{*}{$\begin{array}{l}\text { EU } \\
\text { \% Crec. }\end{array}$} & \multicolumn{2}{|c|}{$\%$ contenido EU } \\
\hline & 1999 & 2000 & & 1999 & 2000 & & 1999 & 2000 \\
\hline Taiwán & 669167 & 86533 & -87.10 & 7156 & 479 & -93.30 & 1.07 & 0.55 \\
\hline México & 178965 & 67060 & -62.50 & 57097 & 49300 & -13.70 & 31.90 & 73.52 \\
\hline China & 2074 & 2277 & 9.80 & 437 & 1588 & 263.80 & 21.07 & 69.74 \\
\hline Isla Santa Lucía & 1337 & 274 & -79.50 & 457 & 120 & -73.70 & 34.18 & 43.80 \\
\hline Corea & 1276 & 90 & -92.90 & 811 & 28 & -96.50 & 63.56 & 31.11 \\
\hline Resto (19 países) & 645 & 173 & -73.18 & 345 & 126 & -63.48 & 53.49 & 72.83 \\
\hline Total & 853464 & 156407 & -81.67 & 66303 & 51641 & -22.11 & 7.77 & 33.02 \\
\hline
\end{tabular}

Fuente: cálculos propios con base en información suministrada por la Comisión de Comercio Internacional de Estados Unidos.

arancelaria en los principales componentes exportadores de la maquila mexicana, sale a relucir nuevamente que China poco a poco se va convirtiendo en un claro competidor.

En el componentes de "aparatos de televisión exceptuando receptores y monitores pero incluyendo cámaras y cables para aparatos de video" el principal proveedor de Estados Unidos es Taiwán, seguido por México, pese a que ambos países muestran reducciones importantes en ese rubro; además, el contenido mexicano dentro de la elaboración de estos productos también es bajo, pues solamente alcanza a ser de $26.5 \%$ respecto del total (véase Cuadro 8). Detrás de esos países, en tercer lugar, se encuentra China, con una participación modesta, ya que solamente contribuye con poco más de dos millones de dólares y nuevamente un alto contenido estadounidense cercano a $70 \%$.

Los otros dos países que ocupan los cinco primeros lugares son la isla Santa Lucía y Corea, pero su aporte es marginal, al igual que los del resto de los 19 países que ingresan exportaciones a Estados Unidos mediante ese régimen. También es sorprendente la alta volatilidad en ese rubro, pues de un año a otro puede haber cambios drásticos que dan muestras de la irregularidad en la demanda y no garantiza estabilidad productiva a los países participantes.

El segundo componente importante dentro del régimen maquilador corresponde a "artículos eléctricos y electrónicos, aparatos y partes no provistos por ningún otro", en el cual se aprecia el claro dominio de México, que aporta más de $80 \%$ de las exportaciones por este concepto, pero nuevamente con visos de reducción frente a años anteriores, aun cuando no parece haber tanta volatilidad en este proceso productivo; en ese renglón, México logra aportar cerca de la mitad del contenido del producto (véase Cuadro 9).

\section{DeSarrollo}


Cuadro 9

Importaciones a Estados Unidos en el régimen 9802 del sA

Artículos eléctricos y electrónicos, aparatos y partes no provistos por ningún otro (miles de dólares)

\begin{tabular}{|c|c|c|c|c|c|c|c|c|}
\hline \multirow[b]{2}{*}{ Países } & \multicolumn{2}{|c|}{ Importaciones } & \multirow{2}{*}{$\begin{array}{l}\text { to tales } \\
\% \text { Crec }\end{array}$} & \multicolumn{2}{|c|}{ Contenido } & \multirow{2}{*}{$\begin{array}{l}\text { EU } \\
\% \text { Crec }\end{array}$} & \multicolumn{2}{|c|}{ \% Contenido EU } \\
\hline & 1999 & 2000 & & 1999 & 2000 & & 1999 & 2000 \\
\hline Iéxico & 1628289 & 1533750 & -5.80 & 922028 & 818821 & -11.20 & 56.63 & 53.39 \\
\hline República Dominicana & 179140 & 166298 & 0 & 131683 & 122373 & -7.10 & 3.51 & 73.59 \\
\hline Irlanda & 57792 & 82241 & 42.30 & 13649 & 18064 & 32.40 & 23.62 & 21.96 \\
\hline China & 37194 & 39464 & 6.10 & 8177 & 6550 & -19.90 & 21.98 & 16.60 \\
\hline Isla de Granada & 11324 & 16604 & 46.60 & 10116 & 13144 & 29.90 & 89.33 & 79.16 \\
\hline Costa Rica & 5006 & 14770 & 195.10 & 3662 & 9045 & 147.00 & 73.15 & 61.24 \\
\hline Malasia & 2926 & 10664 & 264.40 & 1440 & 8967 & 522.60 & .21 & 84.09 \\
\hline Canadá & 8105 & 8871 & 9.50 & 3277 & 4632 & 41.30 & 40.43 & 52.22 \\
\hline Singapur & 5617 & 8237 & 46.60 & 4966 & 7450 & 50.00 & 8.41 & 90.45 \\
\hline El Taiwán & 5282 & 4958 & -6.10 & 2194 & 2140 & -2.50 & 41.54 & 43.16 \\
\hline Filipinas & 2315 & 1911 & -17.40 & 1388 & 851 & -38.60 & 59.96 & 44.53 \\
\hline Alemani & 1839 & 1858 & 1.10 & 1015 & 1180 & 16.30 & 55.19 & 63.51 \\
\hline Indi & 2906 & 1763 & -39.30 & 2080 & 967 & -53.50 & 71.58 & 54.85 \\
\hline Japc & 683 & 1318 & 92.90 & 297 & 990 & 233.70 & 43.48 & 75.11 \\
\hline Hong $\mathrm{I}$ & 3283 & 111 & -6 & 430 & 515 & 19 & 13.10 & 46.11 \\
\hline Resto (38 países) & 5102 & 3827 & -24.99 & 2057 & 1945 & -5.44 & 40.32 & 50.82 \\
\hline $\mathrm{d}_{1}$ & 6803 & 97651 & -3.02 & 84591 & 017634 & -8.19 & 56.65 & 53.63 \\
\hline
\end{tabular}

Fuente: cálculos propios con base en información suministrada por la Comisión de Comercio Internacional de Estados Unidos.

Junto a México, existen otros 38 países que aportan, en conjunto, menos de $20 \%$, de los cuales República Dominicana e Irlanda son los inmediatos competidores, pero juntos no logran aportar más de 250 millones de dólares, mientras que China ocupa el cuarto lugar y su aporte no pasa de los 40 millones de dólares.

Pese a ello, al comparar el contenido nacional neto de las importaciones estadounidenses desde México y China, el primero logra colocar 720 millones, mientras que China, aunque su contenido nacional es mayor (83\%), solamente logra colocar 32 millones netos. Esos datos muestran, entonces, el riesgo que representa China como destino de nueva localización de empresas maquiladoras.

Otro sector líder en la actividad maquiladora corresponde a "partes de vehículos, accesorios y partes también para vías férreas y tranvías", en el cual, pese a que México no es el principal socio comercial de Estados Unidos, logra el tercer lugar dentro de los diez primeros países, todos ellos de alta competitividad y pertenecientes al mundo desarrollado. El principal socio comercial en ese componente es Japón, seguido de Alemania; ambos, en suma, aportan $73 \%$ del total de importaciones estadounidenses. México logra ingresar 2211 millones de dólares, cifra nada despreciable, aunque muestra una caída de $25 \%$ entre 1999 y 2000, pero con un contenido estadounidense de más de $66 \%$, lo cual representa un monto de 1459 millones de dólares (Cuadro 10). Este contenido es, por 


\begin{tabular}{|c|c|c|c|c|c|c|c|c|}
\hline \multirow[b]{3}{*}{ Países } & \multicolumn{7}{|c|}{$\begin{array}{l}\text { Cuadro } 10 \\
\text { ados Unidos en el régimen } 9802 \text { del sA } \\
\text { ías férreas y tranvías y otras partes y accesorios } \\
\text { (miles de dólares) }\end{array}$} & \\
\hline & \multicolumn{2}{|c|}{ Importaciones } & \multirow{2}{*}{$\begin{array}{c}\text { to tales } \\
\% \text { Crec }\end{array}$} & \multicolumn{2}{|c|}{ Contenido } & \multirow{2}{*}{$\begin{array}{l}\text { EU } \\
\% \text { Crec }\end{array}$} & $\%$ Contenido EU & \\
\hline & 1999 & 2000 & & 1999 & 2000 & & 1999 & 2000 \\
\hline Japón & 14101423 & 16905633 & 19.89 & 237847 & 398285 & 67.45 & 1.69 & 2.36 \\
\hline Alemania & 10868084 & 9199508 & -15.35 & 112421 & 69682 & -38.02 & 1.03 & 0.76 \\
\hline México & 2978113 & 2211458 & -25.74 & 1806223 & 1478108 & -18.17 & 60.65 & 66.84 \\
\hline Suecia & 1350592 & 2078766 & 53.92 & 60055 & 41368 & -31.12 & 4.45 & 1.99 \\
\hline Reino Unido & 1428311 & 1662645 & 16.41 & 221608 & 177094 & -20.09 & 15.52 & 10.65 \\
\hline Bélgica & 1430777 & 1060534 & -25.88 & 32360 & 27487 & -15.06 & 2.26 & 2.59 \\
\hline Países Bajos & 367919 & 633554 & 72.20 & 6852 & 1327 & -80.63 & 1.86 & 0.21 \\
\hline Francia & 422980 & 440715 & 4.19 & 10457 & 10353 & -0.99 & 2.47 & 2.35 \\
\hline Canadá & 73707 & 76881 & 4.31 & 37190 & 41499 & 11.59 & 50.46 & 53.98 \\
\hline Austria & 19680 & 59967 & 204.71 & 1129 & 550 & -51.28 & 5.74 & 0.92 \\
\hline China & 20661 & 48667 & 135.55 & 3504 & 14656 & 318.26 & 16.96 & 30.11 \\
\hline Corea & 63752 & 41721 & -34.56 & 29359 & 19910 & -32.18 & 46.05 & 47.72 \\
\hline Taiwán & 64290 & 35532 & -44.73 & 10779 & 6100 & -43.41 & 16.77 & 17.17 \\
\hline Resto (20 países) & 2803 & 4463 & 59.22 & 738 & 1428 & 93.50 & 26.33 & 32.00 \\
\hline Total & $\begin{array}{lll}33 & 193 & 092\end{array}$ & 34460044 & 3.82 & 2570522 & 2287847 & -11.00 & 7.74 & 6.64 \\
\hline
\end{tabular}

Fuente: cálculos propios con base en información suministrada por la Comisión de Comercio Internacional de Estados Unidos.

demás, el más alto dentro de todos los socios comerciales de Estados Unidos en esta franja del régimen maquilador.

China ocupa el onceavo puesto, con un modesto aporte de 48 millones de dólares en 2000 por ese concepto y un crecimiento de más del doble del registrado en 1999; su contenido nacional llega a 70\% pero va aumentando la participación estadounidense dentro del producto final. Ese comportamiento es una muestra de la velocidad a la cual puede crecer una actividad productiva en China y, por ende, en términos de volúmenes todavía no sería una amenaza para México, aunque la industrialización de ese país asiático es crecientemente acelerada y el poder de desplazamiento de competidores en los mercados internacionales aumenta considerablemente.

El último grupo de productos de importancia para la actividad maquiladora corresponde a "maquinaria eléctrica y equipo y partes, registradores legítimos y reproductores, registradores de televisión y reproductores, partes y accesorios", el cual también forma parte de los flujos comerciales que ingresan a Estados Unidos desde el régimen especial con clasificación 9802 del sistema armonizado. Dentro de ese grupo, hasta 2000 México poseía el liderazgo comercial, proveyendo cerca de la mitad de la producción que realizan 89 países. Sin embargo, la caída de más de 32\% de la producción de México podría haber sido alarmante, de no ser porque esta contracción fue generalizada y alcanzó a ser de cerca de $28 \%$ en el total (véase Cuadro 11).

\section{DeSarrollo}




\begin{tabular}{|c|c|c|c|c|c|c|c|c|}
\hline \multicolumn{9}{|c|}{$\begin{array}{c}\text { Cuadro } 11 \\
\text { Importaciones a Estados Unidos en el régimen } 9802 \text { del sA } \\
\text { Maquinaria eléctrica y equipo y partes; registradores legítimos y reproductores, } \\
\text { registradores de la televisión y reproductores, partes y accesorios } \\
\text { (miles de dólares) }\end{array}$} \\
\hline \multirow[b]{2}{*}{ Países } & \multicolumn{2}{|c|}{ Importaciones } & \multirow{2}{*}{$\begin{array}{c}\text { totales } \\
\% \text { Crec }\end{array}$} & \multicolumn{2}{|c|}{ Contenido } & \multirow{2}{*}{$\begin{array}{l}\text { EU } \\
\quad \% \text { Crec }\end{array}$} & \multicolumn{2}{|c|}{$\%$ Contenido EU } \\
\hline & 1999 & 2000 & & 1999 & 2000 & & 1999 & 2000 \\
\hline México & 11385933 & 7714126 & -32.25 & 6020998 & 3787646 & -37.09 & 52.88 & 49.10 \\
\hline Filipinas & 2157905 & 1961035 & -9.12 & 1114476 & 918561 & -17.58 & 51.65 & 46.84 \\
\hline Malasia & 2053442 & 1589948 & -22.57 & 987560 & 876397 & -11.26 & 48.09 & 55.12 \\
\hline Corea & 1731446 & 1175166 & -32.13 & 914509 & 651423 & -28.77 & 52.82 & 55.43 \\
\hline Taiwán & 1480558 & 692508 & -53.23 & 544438 & 355936 & -34.62 & 36.77 & 51.40 \\
\hline Japón & 603395 & 627232 & 3.95 & 289682 & 109304 & -62.27 & 48.01 & 17.43 \\
\hline China & 402696 & 375980 & -6.63 & 150473 & 135793 & -9.76 & 37.37 & 36.12 \\
\hline Tailandia & 467090 & 322968 & -30.86 & 322817 & 218763 & -32.23 & 69.11 & 67.74 \\
\hline República Dominicana & a 227482 & 228965 & 0.65 & 165129 & 169081 & 2.39 & 72.59 & 73.85 \\
\hline Singapur & 147761 & 176218 & 19.26 & 64782 & 71938 & 11.05 & 43.84 & 40.82 \\
\hline Hong Kong & 339348 & 170737 & -49.69 & 164994 & 92000 & -44.24 & 48.62 & 53.88 \\
\hline Resto (78 países) & 374417 & 550198 & 46.95 & 146596 & 196053 & 33.74 & 39.15 & 35.63 \\
\hline Total & 21371473 & 15585081 & -27.08 & 10886454 & 7582895 & -30.35 & 50.94 & 48.65 \\
\hline
\end{tabular}

Fuente: cálculos propios con base en información suministrada por la Comisión de Comercio Internacional de Estados Unidos.

Además, de los 7714 millones de dólares que ingresaron desde México, el contenido nacional representó 3926 millones de dólares, pero de los diez países restantes, considerados los principales proveedores en ese grupo de productos, solamente Japón pudo pasar de $48 \%$ del contenido estadounidense, reduciéndolo a tan sólo 17\%, cuando ocupaba el sexto lugar aun cuando mostró un leve crecimiento respecto del monto de 1999. Por encima de ese país asiático, otros cuatro países de la región — por lo cual la competencia que tiene México dentro de este grupo no solamente se limita a China- Filipinas - en segundo-, Malasia, Corea y Taiwán se disputan un lugar.

Detrás de Japón se encuentra, en séptimo lugar, China, que aportó en 2000 menos de $2.5 \%$ del total, pero si se le agrega lo de Hong Kong, éste asciende a 3.5\%. Tomando esta agregación, entre China continental y Hong Kong logran colocar 545 millones de dólares, pero también, en suma, el contenido estadounidense de esas importaciones alcanza 41.6\%, lo que en términos netos llega a 226 millones de dólares. En ese grupo, pese a que México tiene que competir con la gran mayoría de los países asiáticos, hasta 2000 no había fuerte riesgo de perder el liderazgo, mucho menos con China, que pese a su alto crecimiento, en ese rubro no ha sido amenaza para los intereses mexicanos.

\section{Conclusiones}

Las reformas que ha realizado México no son suficientes para ser un país con estructura competitiva capaz de hacer frente a la amenaza comercial que en la actualidad muestra 
China. De esa manera, las reformas que le permitieron a México alcanzar relativa estabilidad económica y principalmente cambiaria, también le han demarcado una sobrevaloración del peso que no es bien recibida por las expectativas que trae, en el comercio internacional. Las reformas políticas, si bien le han abierto un clima de mayor democracia, tampoco logran el cometido y se pierden junto con los esfuerzos de montar reformas estructurales tanto económicas como sociales. La ausencia de propuestas con un fin social —que apunte a procesos de inclusión que permitan la reactivación de la demanda interna - terminan minando los esfuerzos de los sectores productivos. Las reformas realizadas por China y su proceso de occidentalización moderada le han rendido frutos que actualmente son reconocidos.

La competencia entre México y China dentro del mercado estadounidense tiene dos aspectos que corresponden a las características de sus productos finales y recogen el aporte nacional que los factores productivos de cada país incorporan a sus productos, por ende, tanto la economía nacional como la actividad maquiladora tienen un estado de competencia distinto y un impacto diferenciado por su contenido dentro del producto importado por Estados Unidos. En ese sentido, México tiene dos amenazas desde China: que las industrias maquiladoras que lleguen a nuestro país sean atraídas por China, lo cual corresponde a un efecto negativo dentro de una actividad productiva de baja integración con el resto de la estructura productiva nacional y cuya característica y razón de ser es la generación de empleo; y, segunda, el desplazamiento de productos mexicanos que pueda hacer China y cuyo efecto es más grave que la primera amenaza, debido a que el encadenamiento productivo y los factores de producción involucrados son mayores.

Estas noticias no son agradables, como lo refleja el hecho de que de 2001 a abril de 2003, cerca de 177 maquiladoras instaladas en México se fueron a China, 67 se cambiaron al esquema PITEX y el resto emigró a otros países. ${ }^{4}$ Esto significa que $33.8 \%$ de las maquiladoras que ha dejado de operar en el país se ha ido a China; $12.8 \%$ cambió de esquema y el resto ha emigrado a otras regiones. ${ }^{5}$ Pero este efecto en las maquiladoras no se dimensiona en los niveles del alto y mayor impacto negativo en la industria manufacturera no maquiladora en el país y la destrucción de las cadenas productivas. México debe aprovechar mucho más las ventajas de proximidad con Estados Unidos para sostener su competitividad, pues los productos terminados enviados aquí toman dos días en llegar a Estados Unidos y desde China son cuatro semanas; asimismo, debe analizar el desarrollo productivo y tecnológico de China para reindustrializar su estructura productiva y apuntalar su estrategia competitiva dentro del mercado estadounidense.

\footnotetext{
Según John Christman, director de la firma consultora Global Insight.
}

5 Grupo Reforma, El Paso, Estados Unidos, 26 de julio de 2003.

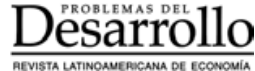




\section{Bibliografía}

Aguilar Camín, Héctor, Después del milagro, México, Cal y Arena, 1988 - México mañana, México, Océano-Nexos, 1986.

Alcántara, Manuel y Antonia Martínez, México frente al umbral del siglo XXI, Madrid, Siglo XXI-Centro de Investigaciones Sociológicas, 1992.

Bustelo, P., "Resultados, interpretaciones y enseñanzas de la reforma económica china (19781998)", en Comercio Exterior, 1998.

, "Progreso sin privatización en China: la reforma de las empresas estatales en los años noventa", en Revista de Estudios Asiáticos, núm. 6, 1996, pp. 117-127.

Bustelo P. y Y. Fernández Lommen, La economía china ante el siglo XXI. Veinte años de reforma, Madrid, Síntesis, 1996.

, "Gradualismo y factores estructurales en la reforma económica china”, documento de trabajo, núm. 9611, Facultad de Ciencias Económicas de la Universidad Complutense de Madrid, 1996, pp. 14-19.

Calva, José Luis (coordinador), Política económica para el desarrollo sostenido con equidad, 2 vol., México, IIEC-UNAM, 2000.

Chai, J.C.H., "China. Transition to a Market Economy”, en Revista de Estudios Asiáticos (monográfico sobre China, con traducciones de trabajos de H.-J. Chang y P. Nolan, D.H. Perkins y A. Singh), núm. 6, julio-diciembre de 1996.

Clavijo, Fernando (compilador), "Las reformas económicas en México, 1982-1999", en El Trimestre Económico, núm. 92, 2000.

Fanjul, E., Revolución en la revolución. China, del maoísmo a la era de la reforma, Madrid, Alianza, 1994.

Feenstra, R.; Hanson G. y Lin. S., The Value of Information in International Trade: Gains to Outsourcing through Hong Kong, Davis, University of California, julio de 2002, p. 4.

Feliciano, Zadia María, Essays on Economic Policy and Labor Market Outcomes: Trade Liberalization, Minimum Wages and Migration. The Case of Mexico, disertación doctoral, Harvard University, 1995.

Funabashi, Y.; M. Oksenberg y H. Weiss, China: una potencia emergente en un mundo de interdependencia, Madrid, INCIPE, 1994.

González Casanova, Pablo, La democracia en México, México, Era, 1965.

González García, J., "China: comercio exterior y crecimiento económico en el camino del mercado", en Comercio Exterior, vol. 46, núm. 12, diciembre de 1996, pp. 981-987.
Guadagni, A.A., China después de Mao. Socialismo $y$ mercado, Buenos Aires, Sudamericana/ Instituto Torcuato di Tella, 1987.

HKCER, "The China Miracle. Executive Summary", en HKCER Letters, núm. 39, mayo de 1996, p. 13, http://www.hku.hk/hkcer/articles/v39/rexe.htm.

Itoh, F. (editor), China in the Twenty-first Century: Politics, Economics and Society, Tokio, United Nations University Press, 1997.

Khan, A.R. y C. Riskin, "Income and Inequality in China: Composition, Distribution and Growth of Household Income, 1988 to 1995", en The China Quarterly, núm. 154, junio de 1998, pp. 221-253.

Leamer, Edward, "The Hecksher-Ohlin Model in Theory and Practice", en Princeton Studies in International Finance, núm. 77, 1995.

Lin, J.Y.; F. Cai y Z. Li, The China Miracle: Development Strategy and Economic Reform, Hong Kong, The Chinese University Press, 1996.

McKinnon, R.I., The Order of Economic Liberalization. Financial Control in the Transition to a Market Economy, 2a. ed., Baltimore, The Johns Hopkins University Press, 1993.

Molinar Horcaditas, Juan, El tiempo de la legitimidad, México, Cal y Arena, 1995.

Naughton, B., Growing Out of the Plan. Chinese Economic Reform, 1978-1993, Cambridge, Cambridge University Press, 1995.

Nolan, P., China's Rise, Russia's Fall. Politics, Economics and Planning in the Transition from Stalinism, Londres, MacMillan, 1995.

Perkins, D. H., "Completing China's Move to the Market", en Journal of Economic Perspectives, vol. 8, núm. 2, 1994, pp. 23-46 [trad. en Revista de Estudios Asiáticos, núm. 6, 1996].

PNUD, Informe sobre desarrollo humano 1997, Madrid, Programa de las Naciones Unidas para el Desarrollo-Mundiprensa, 1997, cuadro 5.

Rawski, T.G., "Implications of China's Reform Experience", en The China Quarterly, núm. 144, 1995, pp. 1150-1173.

Ríos, X., China, ¿superpotencia del siglo XXI?, Barcelona, Icaria, 1997.

Sachs, J. y W.T. Woo, "Understanding China's Economic Performance", NBER working paper, núm. 5935, febrero de 1997. , (1994). "Structural Factors in the Economic Reforms of China, Eastern Europe and the Former Soviet Union", en Economic Policy, núm. 18, pp. 102-145. 
Secretaría de Hacienda y Crédito Público, Deuda externa pública mexicana, México, FCE, 1993.

Shirk, S., The Political Logic of Economic Reform in China, Berkeley, University of California Press, 1993.

Singh, A., "The Plan, the Market, and Evolutionary Economic Reform in China", en A.Abdullah y A.R. Khan (editores), State, Market and Development, Dhaka, University Press, 1996 [trad. en Revista de Estudios Asiáticos, núm. 6, 1996].
State Statistical Bureau, China's Statistical Yearbook 1996, Beijing, China Statistical Publishing House, 1996.

Woo, W.T.; S. Parker y J. Sachs (editores), Economies in Transition: Comparing Asia and Western Europe, The мIт Press, Cambridge, 1997.

Yabuki, S., "China's New Political Economy", en The Giant Awakes, Boulder, Westview Press, 1995.

\section{DeSarrourrollo}

